\title{
Sarmiento: \\ entre Juana Manso y las maestras de los EEUU. Recuperando mensajes olvidados
}

\author{
Sarmiento: \\ between Juana Manso and teachers of the U.S. \\ Recovery of forgotten messages
}

Silvia N. Roitenburd

RESUMO

El escrito propone revisar aspectos del proyecto educativo de Sarmiento, fundante de la instrucción primaria en la República Argentina. Se trata de esbozar algunos apuntes, más allá de su propia figura, que destaquen el papel jugado -en términos de reflexión pedagógica y aún de experimentación en el aula- por Juana Manso, una de sus interlocutoras más cercanas, y por las maestras norteamericanas, convocadas para la apertura de las Escuelas Normales. A este fin se caracterizan aspectos del escenario político en el que se inscribió el ingreso de las primeras maestras de los EEUU para la Nación argentina, aún débilmente conformada. Dentro de ese escenario se inscribe el propósito de incorporar aportes a la comprensión de la lucha por la configuración de un modelo escolar incluyente y la estrategia de matriz clerical, ilustrada en la oposición a la trayectoria de las docentes, materia del presente análisis.

PAlavRAS-CHAVE: Política; Pedagogía; Formación maestras; ofensiva clerical; Sarmiento; Juana Manso.

\section{ABSTRACT}

This paper proposes to revise aspects of the educational project of Sarmiento, founder of primary education in Argentina. This is sketch some notes beyond their own figure, highlighting the role played -in terms of pedagogical reflection and even experimentation in the classroom- by Juana Manso, one of his closest partners and the American teachers, convened for the opening of schools.

For this purpose characterized aspects of the political scene in which registered the entry of the first teachers in the U.S. for the Nation Argentina, even weakly formed. Within this scenario is to incorporate contributions to the understanding of the struggle for shaping an inclusive school model and strategy of the parent church, exemplified in the opposition to the trajectory of the teacher, subject matter of this analysis.

KEYwords: Politics; Pedagogy; Training teachers; Clerical offensive; Sarmiento; Juana Manso.

(...) es cierto que se puede estar contra Sarmiento pero no se puede estar sin él.

Saúl Taborda ${ }^{1}$

\section{Sarmiento: un imaginario politico}

Dado que se trata de una figura tan connotada, parece posible comenzar

\footnotetext{
Doutora em História e Professora da Universidad Nacional de Córdoba (UNC) / Argentina.

1 Saul Taborda (1951: T 3 y 4, 215).
} 
con una advertencia: el escrito no propone un juicio ni definitivo, ni de ningún otro tipo sobre Sarmiento. ${ }^{2}$ Más allá de sus propios límites, dados por su propuesta de una educación en función de un proyecto ideal y la implantación de una experiencia sustentada sobre bases diferentes -la de los EEUU-, un análisis menos centrado en su figura, revelaría algunas nudos sugerentes de indagación. Por ejemplo, la apertura de una tradición docente que enraizó, en ciertos ámbitos del sistema educativo argentino, de modo que merece más atención que la asignada en las historias más difundidas.

Así, se trata de apuntar, más allá de su propia figura, un rasgo relevante de su trayectoria: revisar el papel jugado -en términos de reflexión y aún de experimentación en el aula- por Juana Manso, una de sus interlocutoras más cercanas. Y, por otro lado, las maestras norteamericanas, convocadas para la apertura de las Escuelas Normales.

El propósito principal: rastrear, en sus primeras etapas, el escenario político pedagógico en el que se inscribió el ingreso de las primeras maestras para una Nación, aún débilmente conformada. $\mathrm{Al}$ respecto, resulta pertinente, no sólo dar cuenta de los objetivos expresos -o no-, de Sarmiento, sino presentar el problema abriendo nuevos enfoques posibles. Por una parte, caracterizando el perfil de las docentes, tanto en lo relativo a su experiencia pedagógica pero, sobre todo, a su formación general. Con relación a esto, centrar el análisis en la trama de los discursos que se desplegaron, en particular de la más estructurada oposición, planteada por fracciones de matriz clerical.

Así, más que en el propio Sarmiento, se apunta a dar cuenta de sus relaciones con mujeres de trayectoria educativo-cultural relevante -incorporada

\footnotetext{
2 Domingo F. Sarmiento (1811-1888) fue miembro de la llamada Generación del 37. Más allá de controversias, es considerado el discurso fundante de la educación primaria en su país. Maestro, periodista, escritor, Gobernador de su Provincia -San Juan-, director de Escuelas de la Provincia de Buenos Aires, legislador, llegó a ser presidente entre 1868-1874. En escritos como Educación Común, Educación Popular y muchos otros, abordó aspectos de sus reflexiones en torno a la importancia de la educación masiva, de la formación de maestros a cargo del Estado. Asimismo, durante su Presidencia creó, en la Provincia de Córdoba, sede de la primera Universidad del Río de la Plata fundada por la orden de los Jesuitas, la Academia de Ciencias y el Observatorio, hasta el presente, centros de investigación de primer nivel en la República Argentina. A lo largo de su trayectoria, enfatizó en la necesidad de promover la educación común, gratuita, obligatoria, laica, como aspecto nodal de una política educativa destinada a la formación masiva. Este objetivo lo diferenció de otros miembros de su Generación, como Juan B. Alberdi, con los que compartía el propósito de inserción al mercado mundial. En su dicotomía civilización versus barbarie, resumía su rechazo por la tradición legada por España así como por la población nativa, una de las razones que lo impulsaron, al igual que a otros miembros de su Generación, a promover el ingreso de población inmigratoria, preferentemente procedente del Norte de Europa.
} 
a su condición de maestras. Asimismo, abrir interrogantes sobre su condición de marginadas de las versiones más difundidas de la historia, fuera de menciones sólo circunstanciales.

Ubiquemos el escenario: la expectativa de un desarrollo en una inmensidad territorial que aún debía ser integrada al sistema capitalista, mediante la colonización, inmigración procedente del norte de Europa, y la creación de una infraestructura apropiada -tendido de líneas férreas, creación de un mercado de tierras, estímulo de la inmigración etc.-, crearía las bases de un país inserto en la "modernidad". La incorporación al mercado mundial, objetivo compartido por toda la Generación del 37,3 lo estimuló, a diferencia de Alberdi, a plantear la difusión de la educación popular; la formación del ciudadano así como de valores de la que nombraba como civilización. 4

En una perspectiva más amplia, el curso general del sistema capitalista ocupaba también espacio en sus tribulaciones. El objetivo de integrar el país al mercado mundial ofrecía, a su juicio, dificultades que había tenido oportunidad de apreciar durante su estancia en el Viejo Mundo. El impacto que provocaran en Sarmiento las Revoluciones en Europa y El Manifiesto Comunista de Marx, contribuyeron a profundizar sus dudas acerca de los riesgos que conllevaría la inserción al mundo capitalista. Los múltiples conflictos ocasionados por la Revolución de 1848,5 la radicalización y organización de la clase obrera, el

\footnotetext{
3 Nombramos como Generación del 37 al núcleo de letrados que se reunía en la librería de Marcos Sastre -Echeverría, Juan B. Alberdi, Sarmiento, etc.- participando de un espacio cultural, al modo de los de Europa. Resistiendo a la negativa de Rosas de dictar una Constitución y organizar el país, se plantearon los problemas de la Organización Nacional, en un territorio escasamente integrado y en medio de la anarquía vinculada a la resistencia del Interior enfrentada a la hegemonía porteña. Casi todos, se exiliaron como efecto de la represión desatada por el rosismo. El propósito que los congregaba, más allá de divergencias, se vinculaba con el objetivo de insertar el país al mercado mundial.

4 Sus vetas racistas son inocultables: a su juicio, la población nativa, el indio y su mezcla con la sangre española, el gaucho, reacio a la disciplina laboral que el modelo reclamaba, de los indios y la resistida integración territorial bajo la hegemonía porteña, asumida por los caudillos regionales, representaban trabas decisivas de orden interno.

5 El historiador argentino Tulio Halperin Donghi (1982) atribuye a los historiadores revisionistas haber sido los primeros en alertar sobre la crisis del liberalismo en 1848. Es de advertir que Sarmiento no era nada optimista al respecto. En cuanto a este punto, dejo planteadas algunas consideraciones. Más allá de los alcances de las Revoluciones del período en Europa y su interpretación por los historiadores, en este escrito, interesa visualizar la medida en que los acontecimientos eran procesados, en este caso, por Sarmiento que, en su condición de funcionario de educación del Gobierno de Chile, durante su exilio, viajó por diversos países y extrajo sus propias conclusiones. En cualquier caso dejo en claro que no es el propósito del artículo abordar, ni siquiera aportar a la comprensión de los sucesos en Europa, sino caracterizar el impacto ejercido en su momento, y, sobre todo la incidencia en su proyecto para el espacio desde el que pensaba. Respecto a este impacto, es posible sostener que habría sido
} 
fantasma de una inminente "revolución social" -que parecía una no lejana perspectiva- produjeron el efecto de cierta cautela sobre las consecuencias de los cambios que proponía. No sólo los indios, los gauchos, también la población inmigratoria podría ser portadora de la barbarie. Si embargo, marcando sus controversias con las fracciones más conservadoras del espectro político, llegó a la conclusión de que la educación dirigida a valores compatibles con el trabajo, la producción y un orden que los garantizara, permitiría superar esos efectos. El período de conmociones en Francia de 1847 previo a la Revolución del 48, es analizado según sus manifestaciones en distintas regiones. Sus conclusiones son taxativas:

En todos los departamentos que soportan con tanta calma i resignación las privaciones i los sufrimientos que impone la carestia, la instrucción primaria, de cuyo beneficio participa la casi totalidad de la población, ha desenvuelto desde temprano la inteligencia de los habitantes. Ella les ha enseñado a respetar la propiedad ajena, aún bajo el aguijón del hambre. ${ }^{6}$

Es muy posible que la trayectoria intelectual de Sarmiento hubiera recibido la influencia de la experiencia de la revolución americana, probablemente a través de sus variadas lecturas y del particular interés que, desde muy joven, despertara en él Benjamín Franklin.7 La posibilidad de un desarrollo capaz de evitar la pobreza -hasta entonces evaluada como dato ineludible de cualquier orden social-, 8 la conveniencia de un grado de equilibrio entre los más favorecidos y pobres, nunca indigentes, parece haber ejercido un intenso impacto. $\mathrm{Al}$ respecto, hay que recordar las diferencias entre el proceso

una las razones fundamentales del entusiasmo de Sarmiento por el modelo de EEUU-nudo central del trabajo- y su decisión de incorporar maestras procedentes de ese país. Esta postura es visible tanto en sus escritos dirigidos a argumentar sobre la importancia de la educación masiva, como a través de su correspondencia, que se puede registrar en documentación consultada, en particular periódicos de Córdoba.

6 Domingo F Sarmiento (1856). Se respetó la ortografía del original.

7 Un breve esbozo de esta figura permite vislumbrar su probable identificación con Benjamin Franklin (1706-1790) Periodista, escritor, fue miembro de la Asamblea General de Filadelfia. Participó activamente en el proceso de independencia de los Estados Unidos y en la redacción de la Declaración de Independencia (1776), junto a Thomas Jefferson y John Adams, y se dirigió a Francia en busca de apoyo para continuar la campaña contra las tropas británicas. Allí (fue) nombrado representante oficial estadounidense en 1775, firmó un tratado de comercio y cooperación (1778) y alcanzó el cargo de Ministro para Francia (1779). Contribuye, al fin de la Guerra de Independencia, con la firma del Tratado de París (1783) y en la redacción de la Constitución estadounidense (1787). En 1785 fue elegido gobernador de Pensilvania,. Fue presidente de la Sociedad para Promover la Abolición de la Esclavitud, además, por cierto, de multifacético científico.

8 Sobre la revolución americana y las sugerencias para comprender este aspecto específico, ver Hannah Arendt (2006). 
de la creación de colonias en los EEUU y la conquista de la América española. 9

Esta perspectiva revela una visión extendida del escenario en el que planteaba su proyecto - un territorio que debía ser integrado para incorporarse al mercado mundial-y, como clave nodal, la difusión masiva de la educación. Escenario extendido en más de un sentido: no sólo económico sino en su vinculación con la cultura universal y la incorporación de avances científicos, y su recepción.

En ese contexto, los escritos -a los que accediera en Chile- cuanto la información sobre la obra educativa de Horace Mann, parecen haber sido decisivos. Es a partir de ese interés que se plantea el vínculo en términos de reflexión con mujeres no menos letradas que algunos de sus contemporáneos.

Propongo para el análisis la medida en que tales interlocutoras aportaron significativamente en sus propósitos dirigidos hacia la cultura, atribuyendo a la educación un rol central, incluyente, superando, incluso, los límites de muchos de los miembros de la llamada Generación del 37. A ese fin, su propia lucha por ser incluidas en un mundo de hombres, sumada a una sólida formación pedagógica, fue puesta en juego en la práctica concreta dentro de la escuela.

\section{Juana Manso: una educadora latinoamericana (1819-1875)}

En la primera mitad del siglo XIX, hasta la década del 60, cuando ubicamos el proceso más decidido de formación nacional, se detectan, en las distintas provincias, manifestaciones que, aunque fragmentarias, revelan interés en la difusión de la educación. El escenario previo a la llegada de las maestras norteamericanas y simultáneo a la trayectoria de Juana Manso indica el despliegue de actividades, en diversos espacios regionales -Sociedades de Fomento de la Educación, creación de Departamentos de Escuelas, Comisiones de Beneficencia que apoyaban la creación de escuelas, etc.

La condición de Rosas de gobernador de Buenos Aires, entre 1829-1832 y $1835-1852,{ }^{10}$ su capacidad de construir hegemonía ${ }^{11}$ en el Interior ${ }^{12} \mathrm{y}$, por cierto,

\footnotetext{
9 En este caso, el valor negativo asignado al trabajo manual por parte de la nobleza feudal, era una de las razones por las que rechazaba la tradición legada por España.

10 Juan Manuel de Rosas - ganadero, poderoso estanciero de su provincia- fue Gobernador de Buenos Aires entre 1829-1832 y 1835-1852. El ejercicio de facultades extraordinarias, que le fue otorgado, en una situación de anarquía que impedía la Organización Nacional, y su gran capacidad de influencia sobre el Interior -aún, como es el caso de Córdoba, nombrar un
} 
el rol central de su provincia en el contexto de regiones desarticuladas, le otorgan particular importancia. El estado de la educación durante su gobierno exhibe el deterioro de todos los niveles educativos, ${ }^{13}$ el cierre de escuelas y el control sobre las que permanecieron. ${ }^{14}$

Cabe registrar un aspecto de particular interés para el enfoque propuesto. El nombramiento de Marcos Sastre como Inspector General de Escuelas en 1850 , remite a un faceta fundamental referida al perfil docente instaurado:

\begin{abstract}
Los nombramientos de maestros y ayudantes se hacían por examen $o$ por concurso ante la Junta Directora o de comisiones inspectoras en presencia del Inspector General como examinador, exigiéndose como requisitos indispensables: Profesión de fe católica, buenas costumbres, buen carácter e instrucción suficiente. (SALVADORES, 1941: 241). 15
\end{abstract}

Esta escueta y, presuntamente obvia, mención a las buenas costumbres, es menos de lo que a simple vista se puede suponer: permite vislumbrar una cuestión que, en adelante, se planteará como uno de los conflictos centrales del modelo educativo: ¿quién define las buenas costumbres? ¿Cuál es la moral y valores válidos que deben difundirse desde la escuela hacia toda la sociedad?

$\mathrm{Su}$ equivalencia con la profesión de fe -excluyente- abre un extenso conflicto que refiere a los valores que deberían regir en toda la sociedad, que, a su vez, se vinculan, íntimamente, con el asignado a las maestras, habida cuenta del rol de la mujer, como sabemos, en adelante, figura protagónica en el ámbito escolar.

Complementariamente, las indicaciones diversas en cuanto a los saberes a transmitir dentro de la escuela, abren líneas en igual dirección.

La enseñanza comprende las siguientes materias: doctrina cristiana explicada e instrucción para recibir los sacramentos, moral y urbanidad, lectura, escritura, elementos de aritmética comercial y

Gobernador afín, que fue derrocado a su caída- le dieron un poder que ningún gobierno había logrado desde el período de la Independencia. Dentro de los exiliados por la oposición a su gobierno y la consecuente represión de que fueron objeto, se encuentran -entre muchos otrosDomingo F. Sarmiento, Juana Manso y su familia así como el también citado José Mármol.

11 En el sentido de los análisis gramscianos.

12 Cuando escrito con mayúsculas, alude a la región que habitualmente se oponía a las provincias del Litoral

13 Decadencia visible en la Universidad, a su vez, afectada por el exilio de buena parte de los letrados (Halperin Donghi, 1962).

14 Para información más detallada, sobre la educación y creación de escuelas en el período, ver Antonino Salvadores (1941).

15 Cursiva del autor citado. 
gramática castellana con las reglas de ortografía. En las escuelas de la campaña y en las de mujeres, en lugar de aritmética comercial se enseñaran las cuatro operaciones elementales y a las niñas labores propias del sexo. (SALVADORES, 1941: 242). ${ }^{16}$

De tal modo, en un escenario político signado por constantes enfrentamientos facciosos y persecuciones, con efectos consecuentes sobre todos los niveles de la educación, Juana Manso, muy joven, colabora con la Sociedad de Beneficencia Educativa(.), (I)institución que, entre otras actividades culturales, había fundado escuelas en Buenos Aires, en zonas entonces más pobladas.

Miembro de una familia anti-rosista, sufre el exilio ${ }^{17}$ a los 20 años. Es probable que esta experiencia, traumática -y reiterada en diversos períodos de la historia argentina-, la hubiera preparado para una vida agitada y viajera, no siempre placentera. A lo largo de sus exilios, viajes y circunstancias familiares adversas, desplegó una constante actividad en todos los aspectos de la cultura.

Destaco algunos episodios relevantes de una vida particularmente compleja, poco usual en su época. En 1841, exiliada junto a su familia en Montevideo, en dos habitaciones de su propia casa, funda el Ateneo de las Señoritas, destinado a jóvenes y señoras que aprendían aritmética, lectura, labores, lecciones de moral, gramática, francés, piano, canto y dibujo.

El sitio de Montevideo, en 1842, la obliga, junto a su familia, a exiliarse nuevamente, esta vez en Brasil. En 1844 regresa a Montevideo donde es nombrada directora de una escuela de niñas.

Una nueva estadía en Brasil implicó, además de una amplia producción literaria -difundida con éxito desparejo-, una activa oposición a la esclavitud, aún vigente en ese país, e, consecuentemente, a favor de la emancipación.

Casada en ese país con Francisco de Saá Noronha, ${ }^{18}$ allí publica tratados filosóficos, obras teatrales, algunas en portugués, como La Familia Morel, A Saloia, A Esmeralda, Rosas, y otros escritos, obteniendo varios éxitos. En 1851 funda y publica su primer semanario Jornal das Senhoras, con poemas, crónicas, sociales, partituras, artículos dedicados a la educación de la mujer, etc.

16 Idem.

17 Su padre, José María Manso, había participado de las luchas revolucionarias y, en adelante, del gobierno de Bernardino Rivadavia.

18 Con su marido viajó por Estados Unidos, Cuba y otros países. Tuvo dos hijas de las que debe hacerse cargo cuando, en 1852, su esposo las abandona, regresando con ellas a Buenos Aires. 
En 1858, fue su amigo, el escritor José Mármol, quien le presentó a Sarmiento, entonces preocupado por encontrar a la persona con trayectoria apropiada para dirigir una institución educativa. La nombró directora de la recientemente fundada Escuela de Ambos Sexos $\mathrm{N}^{0}$ 1, donde aplicó la experiencia de coeducación.

Casi al mismo tiempo, el futuro presidente crea la Revista Anales de la Educación, convirtiéndola en su colaboradora fundamental. Publicación cuyo fin era difundir nuevos planes de enseñanza, reflexiones vinculadas a diferentes modelos educativos, etc. Su dominio del inglés, le permitió traducir y publicar en sus páginas, por ejemplo, Lecturas de Horace Mann.

En 1862, escribió el Compendio de la Historia de las Provincias Unidas del Río de La Plata, primer manual de historia con lenguaje sencillo para los primeros años de enseñanza. Es probable que hubiera sido parte de un intento de elaboración de una más ambiciosa producción historiográfica. Sin embargo, su libro de historia no parece haber resistido la ofensiva hegemónica del padre de nuestra historia, Bartolomé Mitre.

Su trayectoria multifacética se revela en una amplia producción literaria y periodística. Durante 1864 escribió en el semanario Flor del Aire una página de la sección a su cargo "Mujeres Ilustres de la América del Sud". Allí rescató la vida de mujeres que lucharon por la independencia y la libertad como la Alférez Manuela Pedraza y la Teniente Coronel Juana Azurduy. También escribió el drama teatral La Revolución de Mayo de 181o, combinando un escenario histórico en su obra literaria. En el relato Margarita, exhibe una veta crítica, poco frecuente en la literatura de época; a través del mismo, reflejaba la hipocresía de las relaciones de pareja en el siglo XIX.

En 1865, escribe La escuela de Flores, donde abundan duras criticas a los gobiernos latinoamericanos por no destinar los fondos suficientes a la educación.

Su paso por Filadelfia, en viajes con su marido, le habían dado acceso a diversos contactos y núcleos de cultura. Experiencia que la estimuló cuando, en 1869, escribe Curso graduado de instrucción en las escuelas graduadas de Chicago para servir de modelo a las de la República Argentina. Respecto a este material y su difusión, remiten al rol fundamental jugado por esta educadora en su época y, no es difícil sospechar, la influencia que habría tenido sobre 
Sarmiento, en particular, en el proyecto del presidente de contratar maestras de los EEUU.

Fue la primera mujer vocal del Departamento de Escuelas en 1869. Se destaca, dentro de su propósito de institucionalizar, de acuerdo a criterios acordes basados en una pedagogía democrática, la propuesta de introducir los concursos, para cubrir los puestos directivos. Dentro de ese objetivo, promovió un proyecto de profesionalización docente en la legislatura de Buenos Aires.

Durante la gestión de Sarmiento como presidente, fundó 34 escuelas con Bibliotecas Públicas.

Disgregando, un tanto, el relato, y retomando la información antes enunciada, veamos su lugar dentro de otros miembros de su generación, distinguidos por la historia cultural.

Fue, quizás, la primera escritora -en el Río de la Plata- que produjo una serie de novelas históricas con trasfondo político. Publicó semanalmente poesías y otros escritos, bajo diversos seudónimos. Se trata de escritos que precedieron en unos cinco años, por ejemplo, a la novela histórica Amalia, obra muy difundida de José Mármol, ${ }^{19}$ cuya primera parte se publicó en 1844 y sólo años más tarde la obra terminada. En adelante, durante décadas -buena parte del siglo XX- será material obligado de lectura en las escuelas del nivel medio del país.

El propio José Mármol fue, sin embargo, quien la instó a escribir Identificada con el romanticismo ${ }^{20}$, corriente en la que él mismo se inscribía. Este estímulo, fundado en una positiva apreciación de una obra que conocía bien, no obstó la diferente trascendencia entre ambos autores por parte de una historiografía que poco la recuerda. En esta línea de interrogantes, referidos al opacamiento de su obra en la Argentina -en las historias de la cultura, de la literatura, de la educación, etc.- frente a la de sus iguales hombres queda ilustrada con otros elementos de juicio. Es interesante consignar que su novela Los misterios del Plata, de 1846, se publicó pocos meses después de la aparición del Facundo de Domingo F. Sarmiento. Si bien es probable que la obra literaria

19 José Mármol (1818-1871), como se aprecia, tenían la misma edad. También exiliado en Río de Janeiro -residió en la capital carioca hasta febrero de 1843-, constituyó uno de los paradigmas de la literatura romántica de su época. Fue uno de los más conocidos escritores anti-rosistas

20 Echeverría había sido la inspiración fundamental de los más jóvenes miembros de la Generación del 37 y difusor del romanticismo, hasta su muerte, en 1851. 
de Sarmiento supere la de todos sus contemporáneos ${ }^{21}$ no deja de resultar extraño el hecho de que, en adelante, su obra como escritora, casi, no fuera mencionada.

En cuanto a su perfil como educadora, su trayectoria también es destacada.

Precursora, en nuestro país, de la lectura de la pedagogía "moderna", propagó los principios de Pestalozzi y Froebel, procurando difundirlos y aplicarlos en sus experiencias. Innovadora en sus prácticas, apuntó contra los métodos instaurados. Otorgó especial importancia a la actividad libre del niño, a despertar su interés y espontaneidad. Enemiga decidida de los castigos corporales -en circunstancias en que el modelo escolar aún se basaba en ellosy en el clima de temor que caracterizaba la tradición educativa, ${ }^{22}$ expuso sus posturas mediante escritos y participación en debates que la ubicaron como uno de los blancos de los sectores reacios a las transformaciones.

Fue una de las primeras docentes que llevó a cabo la experiencia de coeducación, uno de los conflictos más largamente controvertidos en la historia de la educación argentina, que llevó a la práctica en la Escuela Mixta en Buenos Aires, 1858 , con la consecuente confrontación -de la que fuera objeto a lo largo de su trayectoria- por parte de núcleos de matriz clerical

En conexión con esos propósitos perfiló el rol de maestro: lo visualizó, no en la función disciplinante, asignada en discursos conservadores que procuraban reafirmarse, sino como generador de un clima escolar apropiado para estimular el trabajo autónomo de los alumnos. Promovió el aprendizaje basado en la observación y la reflexión, el respeto a las necesidades y grados de maduración del niño, puesta en juego en el trabajo en la escuela. En su propia experiencia como maestra, asignó especial importancia a la actividad libre del niño, el interés y la espontaneidad. Pensó en el maestro como generador de un ambiente cálido y confortable para guiar y sugerir el trabajo del alumno. En ese sentido, es una precursora, en nuestro país, del examen de un nudo problemático que se desplegara, unos años más tarde, en el debate de la ley

\footnotetext{
${ }^{21}$ Excede los objetivos de este artículo una crítica literaria más específica.

${ }^{22}$ Ver en este artículo aspectos del debate de la Ley 1420.
} 
1420. ${ }^{23}$ En adelante, constantemente reactivado al calor de las luchas por la imposición de un modelo escolar normalizante y los intentos de experiencias alternativas que lo replanteaban.

Son muchos los indicios de su propio entusiasmo por Horace Mann. Hay que recordar que había residido con su marido brasileño en Filadelfia, estimulada por el efecto operado en ella por un ámbito cultural inusual en su tierra, reavivado, en frente, por la correspondencia que ella misma mantuvo con Mary Mann.

De este modo, se vislumbran conexiones y/o estímulos, sobre un Sarmiento que compartía con ella reflexiones, impresiones, en diversos tópicos referidos a la cultura, la literatura, la educación.

Finalmente, hay que decir: las alusiones a su trayectoria son fragmentarias, ocasionales y nunca adquieren el lugar que la misma parece requerir. Como ejemplo significativo, uno de los materiales bibliográficos que ofrece información más sistemática sobre la Instrucción Primaria del período en el que actuó, la menciona así:

\section{(...) dentro del círculo que siguió fiel a sus ideas (las de Sarmiento) (...) debe destacarse a Juana Manso que desde 1860 mantuvo en tensión constante a la opinión pública (SALVADORES, 1941: 286). ${ }^{24}$}

Sugerente por lo que omite, remite a las duras acusaciones, de las que fuera objeto a lo largo de su trayectoria, por la opinión pública, que el autor de la frase prefiere no identificar.

Que Juana Manso hubiera sido materia de una dura oposición, en su intento de llevar a cabo la experiencia de coeducación en una escuela de Buenos Aires, es, mucho menos que una anécdota más, indicio de la presencia de figuras que se planteaban problemas de revisión de los modelos vigentes que, además, eran mujeres. En los años en los que se desplegó su práctica, tanto en lo referido a labor literaria, periodística como educativa recibió las más diversas acusaciones: entre la de extranjerizante y subversiva de nuestros valores, hasta las más sarcásticas, de grueso tono, en ocasiones, que referían del modo más

\footnotetext{
23 Debate reiterado, en términos comparables, en los años 30 y 40 en la Legislatura Córdoba, en el marco de un proyecto de reforma educativo- cultural, en el que se recuperaban aspectos sustanciales del reformismo crítico procedentes del movimiento de 1918 en la Universidad de Córdoba.

24 Negrita del autor citado.
} 
denigrante a su desvío de su rol de madre y, aún, a su condición de esposa abandonada. En todos los casos, el significado atribuido a la condición de mujer pública, era claramente diferenciado de la condición -sin duda digna- del hombre público. 25

Se trata de un nudo problemático que, por el momento, sólo queda esbozado.

Juana Manso muere a los 55 años, en medio de graves dificultades personales. Para reafirmar las hipótesis en cuanto a su figura, vista en su época, vale la pena consignar la despedida, ante sus restos, de la poetisa Juana Manuela Gorriti, ${ }^{26}$ mediante una evocación a través de la que recupera su legado de lucha:

Juana Manso gloria de la educación, sin ella nosotras seríamos sumisas, analfabetas, postergadas, desairadas.

Sólo de paso y cerrando, provisoriamente, un aspecto que merece ser profundizado, la propia trayectoria de quien la despide, abre interesantes interrogantes respecto a mujeres en el espacio de la cultura y la educación, relegadas de nuestra historia. Juana Gorriti fue, cronológicamente vista, la primera novelista argentina. Desarrolló múltiples actividades: viajera, periodista y promotora de actividades culturales. Casada a los 15 años con un militar peruano, en 1845 publicó una novela corta, La quena, en la Revista de Lima, a partir de lo cual no interrumpiría nunca su actividad literaria. En Perú, fundó una escuela y convirtió su casa en un salón literario. Sus cuentos y novelas fueron publicados y difundidos en Chile, Colombia, Venezuela y Argentina y, luego de la caída de Rosas, también en Madrid y París. En 1874 separada de su marido, situación excepcional en su época- se estableció en Buenos Aires, donde se dedicó a recopilar e imprimir su producción y a escribir relatos autobiográficos.

Breve reseña, de información fragmentaria, para destacar un aspecto que merece ser profundizado: el rol activo - de resistencia al orden vigente- que se aprecia en mujeres que, usualmente, por su procedencia de clase tenían acceso a la cultura y habían logrado, aunque con dificultades, ganar un espacio. Un rasgo

\footnotetext{
25 Ver El Eco de Córdoba de los años 1862 hasta su muerte.

26 Juana Manuela Gorriti nació en Salta (1818) y murió en Buenos Aires (1892). Hija del general José Ignacio Gorriti y sobrina del canónigo Juan Ignacio Gorriti, pertenecía a una familia enraizada en las luchas de la Independencia.
} 
que las identifica: sus intentos de difundir la educación, ampliando esos propósitos a la integración en la cultura de sectores marginados.

\section{Las maestras norteamericanas 27}

En agosto de 1847, Sarmiento se encontraba en Londres, luego de haber recorrido varios países europeos en su afán de recopilar información sobre los últimos adelantos educativos. Allí había llegado a sus manos el Informe de un viaje por Alemania, Francia, Holanda y Gran Bretaña de un norteamericano, Mister Horace Mann (1796-1859). Mediante el mismo, comunicaba a la Junta de Educación de Massachussets las experiencias y los resultados que había obtenido durante el viaje cuyo propósito había sido, también, la investigación de los sistemas educativos de Europa. Es probable que él ya conociese, desde su exilio en Chile, alguna referencia a la obra del educador; estaba al tanto de su trayectoria como organizador de la instrucción en Massachussets y en la formación de miles de maestros. Esto, sumado a escritos en los que Mann argumentaba sobre la importancia de la educación común, contribuyó a una admiración casi sin límites, de acuerdo a su estilo apasionado.

En su primera visita a Estados Unidos, ${ }^{28}$ desde septiembre a octubre de 1847, Sarmiento parece haber visto encarnado su ideal de la civilización. Conoció a Mann en su casa de West Newton cerca de Boston. El escenario de este encuentro, decisivo para la forma que tomaría su proyecto, aún en una etapa preliminar, merece unos párrafos. Boston ${ }^{29}$ era, al promediar el siglo XIX, un ámbito de desarrollo social y cultural de notable envergadura. Nueva Inglaterra, una región en ebullición cultural, era espacio de debate de problemas políticos, sociales, económicos y culturales donde predominaban posturas de las que salieron, por ejemplo, movimientos como el antiesclavismo, $3^{\circ}$ el sufragismo

\footnotetext{
27 Si bien, como sabemos hubo algunos hombres, finalmente, las huellas que dejaron permiten un análisis centrado en ellas. Casi toda la información disponible, difundida en nuestro país, acerca de las maestras norteamericanas, ha sido recopilada por Alice Houston Luiggi (1959).

28 El chileno Santiago Arcos -el mismo a quien Mansilla dedica su Excursión a los indios ranqueles-, con quien se encontró en Liverpool, le facilitó los fondos para el viaje, llevado a cabo por el interés en visitar los EEUU, fuera de todo mandato oficial.

29 Es la capital y ciudad más poblada de la Mancomunidad de Massachusetts y también es la ciudad más grande de la región de Nueva Inglaterra.

30 La llamada Guerra de Secesión que culminó con la liberación de los esclavos se desarrolló entre 1861-1865.
} 
y el feminismo norteamericano.

Es necesario señalar: en lo sucesivo, Sarmiento si bien mantendrá correspondencia, no volverá a encontrarse con Mann que muere unos años más tarde. En cambio, el vínculo se mantuvo con su esposa Mary que, al principio, había hecho posible la comunicación entre ellos ya que, entonces, Sarmiento, que tenía dominio del francés, apenas conocía el inglés. Convertida en su anfitriona, hizo lo que a su visitante más le agradaba: ponerlo en contacto directo con los círculos intelectuales que ella misma frecuentaba junto a sus hermanas Elizabeth y Sofía Peabody. ${ }^{31}$ La fascinación de Sarmiento, sumergido en un clima cultural selecto, en el que se sentía a sus anchas, fue un recuerdo imborrable, que nunca lo abandonó. ${ }^{2}$

Desde entonces, se convirtió en su amiga, interlocutora directa o epistolar, en las que planteaban dudas, reflexiones y comentarios personales. En síntesis, colaboradora fundamental para el proyecto del que se sentía parte. Que Mary se moviera en un ambiente intelectual de esas características -con influencia del Trascendentalismo de Emerson33, que participaba de ese círculo- no es un dato menor. Tampoco, el interés por la pedagogía articulada con la formación filosófica, concebidas como condición fundamental a considerar en la selección de maestras.

En Viajes por Europa, Africa y América 1845-47,34 Sarmiento, si bien transmite su interés por la obra del educador que inicialmente lo había inspirado, destaca con particular énfasis el impacto provocado por las mujeres con las que había entrado en contacto. En carta a Horace Mann manifiesta su asombro por su participación en actividades culturales, su formación científica

31 Mary Peabody (1806-1887) nació en el seno de una familia de Salem, ciudad del Estado de Massachusetts cercana a Boston. Con sus dos hermanas: Elizabeth Peabody (1804-1894) y Sophia Peabody (1809-1871) formaron parte de un círculo de destacados intelectuales.

${ }^{32}$ Siempre mantuvo la expectativa de volver. Así lo manifiesta en su correspondencia a Mary "Los periódicos que me envían me tienen al corriente del movimiento intelectual tan activo de los Estados Unidos y mi placer redobla cuando me encuentro con los nombres de mis conocidos Emerson, Miss Peabody, (...) Cuánto diera por oírlos! Cuánto por al elixir de vida, de manera que cuando pudiera volver no seamos viejos. Ud y yo, dos viejos, temblorosos y ciertas damas que me gustaban mucho, no me miren como un monumento de lo pasado".

33 Nació en Boston (1803) y murió en Concord (1882), fue un escritor, filósofo y poeta estadounidense.

34 Para este escrito, he tomado, a veces en forma literal, la reproducción de correspondencia o escritos de Sarmiento, que el diario El Eco de Córdoba difundiera, integrada en sus propios objetivos editoriales, entre los años 1862 hasta 1880. En cuanto a la información biográfica sobre las maestras, remitimos al ya citado libro de Alicia Houston Luiggi. 
y erudición, su entusiasta labor en la transmisión de sus saberes, y, sobre todo, su voluntad de valerse por sí mismas.

(...) visité con su señora (...) un plantel de maestras y donde, no sin asombro, vi mujeres que pagaban una pensión para estudiar matemáticas, química, botánica y anatomía, como ramos complementarios de su educación, debiendo pagarlo cuando se colocasen en las escuelas como maestras(...)

En otros casos, encontraba figuras femeninas que también lo entusiasmaban: en Chicago, el apoyo de la Sra. Kate Newal de Dogget fue, también, importante. Activa y multifacética, recorría una trayectoria que pondría en juego en su colaboración. Promotora del sufragio femenino, botánica experta y miembro de la Academia de Ciencias de Chicago, participaba en espacios que, en su país, eran inusuales para las mujeres.

De tal modo, fue, sobre todo, el perfil de Mary Mann y otras interlocutoras que lo apoyaron en esa tarea, decisivo para sus expectativas. Bien informado acerca de otras experiencias educativas, como la de Prusia, que había fundado sus Escuelas Normales a principios del Siglo XIX, su entusiasmo por el modelo de los EEUU, se reafirmó.

Por su parte, Mary Mann compartía con Sarmiento la necesidad de la contratación de maestras "como sustento de la educación primaria"; tanto como el criterio esbozado por éste para la selección de quienes debían ser maestras de maestras.

Las buscábamos, de aspecto atractivo, maestras normales, jóvenes pero con experiencia docente, de buena familia, conducta y morales irreprochables y, en lo posible, entusiastas y que hicieran gimnasia, para enseñar a nuestras criollas, tan acostumbradas a estar inmóviles, asistidas por su servidumbre, a usar su cuerpo al modo de los griegos, valorizándolo y glorificándolo. 35

No parece haber sido fácil hallar candidatas convencidas de viajar, en especial teniendo en cuenta que Mary había tomado muy en serio su tarea y exigía las mejores calificaciones así como antecedentes personales irreprochables.

Para llegar, debían afrontar un viaje largo e incómodo que primero tocaba puertos europeos. Algunas tenían algunos conocimientos de español; recién llegadas, recibían una especie de "curso de adaptación" en Paraná, donde

35 Cartas de Viajes. Es de consignar que el diario El Eco de Córdoba, vinculado al núcleo clerical de la provincia, en todo el período previo a la asunción de Sarmiento como Presidente y en adelante, reproducía cartas lo que permitió una investigación a partir de correspondencia, material que no siempre es accesible para los historiadores. 
aprendían o profundizaban el idioma local.

Es difícil saber hasta qué punto Sarmiento había sido claro respecto a las condiciones del territorio en el que debían dispersarse. En teoría, los sueldos que se acordaron eran adecuados. Los términos de los contratos indicaban que tendrían una duración de tres años y podrían ser renovados de común acuerdo. Las maestras también podrían dar cursos públicos de inglés o lecciones de manera particular. Se solicitaba que, antes de ir a Paraná, se elaboraran los planes de estudio para la escuela normal.

Sin embargo, las condiciones eran bastante más complicadas: Entre Ríos era escenario de la guerra entre López Jordán y las tropas nacionales y, como sabemos, el territorio era escenario de luchas cuya resolución aún era incierta. Si la segunda mitad del siglo XIX se caracterizó, sobre todo hasta 1880, por una sucesión de luchas cruentas - con los llamados caudillos del Interior, los ataques de los malones indios, las luchas facciosas- el asesinato de Urquiza, en 1870, año de la apertura de la Escuela Normal de Paraná, sintetiza las palpables condiciones de violencia. Ex presidente y uno de los hombres más poderosos de su provincia, Entre Ríos, y, aún de toda la región porteño-litoral, fue un hecho electrizante que, adicionalmente, se produjo en simultáneo con el de varios de sus hijos. No es difícil imaginar la impresión terrible que habría producido el acontecimiento en quienes llegaban para abrir, precisamente, escuelas.

En carta a Mary Mann, precisamente de 1870 -poco después del asesinato de Urquiza-, Sarmiento le escribe sobre la negativa de Miss O Gorman a viajar a San Juan. ${ }^{36}$

Temo que la resistencia a ir a Córdoba nazca de informes dados por R. Goodfellow 37 que fue muy mal recibido. Tiene en ello razón, pero hemos de hacer desaparecer la razón, que es más aparente que real. ${ }^{8} 8$

Sabemos que era imprescindible una alta cuota de optimismo para pensar que la/s dificultad/es era/n más aparente/s que real/es y una fe ciega en que el conflicto se iba a superar. Sin duda, se equivocaba.

36 Dicho sea de paso, la propia Juana Manso la había apoyado contra la vehemencia de Sarmiento que parecía no dar cuenta de tales condiciones de inseguridad.

37 Alude al Rev. Metodista Guillermo Goodfelow nombrado, en 1856, superintendente de la Misión en Sudamérica. En el cumplimiento de la tarea encomendada, Goodfelow promovió la organización de la Sociedad Bíblica Americana y también colaboró con el reclutamiento de maestras y profesoras en los Estados Unidos para las Escuelas Normales organizadas por Domingo F. Sarmiento. Fomentó la extensión de la obra en Paraguay -durante la Guerra de la Triple Alianza- y cooperó con las misiones anglicanas de la Patagonia y Tierra del Fuego.

38 Ver transcripción en El Eco de Córdoba, enero de 1871. 
Finalmente, para las que se atrevieron, nada fácil fue el viaje y la instalación. En cualquier caso era una aventura que, por lo visto, algunas, bien o mal informadas, estaban dispuestas a vivir, fuera movidas por el propósito de extender los beneficios de la educación y/o por razones personales diversas.

Más allá de la supuesta osadía que, desde la perspectiva más conservadora, se atribuía a mujeres que viajaban solas, es decir sin padre o marido, nada indica que ninguna de ellas excediera los criterios de moralidad y buenas costumbres propios de lo que el discurso hegemónico atribuía a una dama. Todas eran de lo que se daba en llamar de buena familia: es decir con un buen nivel de cultura aunque, en algunos casos, atravesaran dificultades económicas. Por otra parte, de acuerdo a las costumbres de época, las señoritas eran encomendadas a alguna Señora confiable, fuera la esposa del cónsul u otro funcionario. Algunas de ellas se casaron, ninguna con un nativo, y formaron, con sus hijos, familias formalmente establecidas.

Menciono sólo algunos nombres cuya trayectoria contribuye a ilustrar sobre los rasgos que interesa destacar en la perspectiva abordada. Una de las primeras maestras que llegó al país durante la presidencia de Sarmiento, Serena Frances Wood, muerta a pocos meses de desembarcar en Buenos Aires, en el verano de 1871, durante la epidemia de fiebre amarilla, tenía antecedentes dignos de consideración. Cuatro años antes, luego de dejar su docencia en una escuela en Massachusetts, había fundado la primera escuela para esclavos libertos 39 en Virginia, de la que salió airosa. Por cierto, con la oposición de muchos blancos que la quisieron intimidar. ${ }^{40}$

Por su parte, Clara Bischoff dejó, en Rosario, una memorable experiencia educativa: se la recuerda por sus avanzados criterios de pedagogía escolar. No había en su escuela distinción de razas, de nacionalidad, de religión o de ideario político; no había uniformes ni insignias; no había promedios ni amonestaciones, ni siquiera un régimen de inasistencia ya que concurrían los que podían hacerlo. Una heterodoxia imperdonable que le valió duras críticas.

39 La liberación de los esclavos, después de la citada Guerra de Secesión, trajo consigo el desafío de educar a los mismos, que hasta entonces tenían prohibido el acceso a todos los niveles de la instrucción.

40 Reproduzco el fragmento de Luiggi: "Sin acobardarse, había desafiado amenazas y verdaderos asaltos de miserables blancos, timoratos y celosos y tenía en la sien una larga cicatriz de una pedrada que le arrojaron" (1959: 87). 
A juzgar por las Memorias de la señorita Howard,41 se tenía una idea confusa de la Argentina. Ella misma -que provenía de una acomodada familia de Boston- desde joven había exhibido tanto su interés por la pedagogía y su aplicación en la escuela cuanto su firmeza expuesta, por ejemplo, al reorganizar una escuela de varones conocida por su indisciplina.

En cuanto a Sarah Eccleston (1840-1916), abrió una tradición que perdura. Nacida en Pennsylvania, fue la encargada de desarrollar, con éxito, las propuestas de Elizabeth Peabody ${ }^{42}$ en la Argentina, fundó los Jardines de Infantes y luego la Sociedad Froebeliana Argentina, además de representar al país en la Conferencia Mundial de Educación de 1897, donde, muy probablemente, se habría reunido con María Montessori.

Finalmente, desde otra perspectiva, para cerrar provisoriamente un aspecto que debe ser profundizado, retomando la anterior mención al clima bélico de la época, hay que agregar, que la intolerancia manifiesta por distintos medios, fue uno de los factores más impactantes que afectaron a las jóvenes de modo inesperado. Las impresiones de Jennie Howard, antes citada, pueden ser vistas como las de una extranjera, que procura comprender el lugar al que llegó. Destinada a Córdoba relata este episodio:

en la puerta de la iglesia de los jesuitas se leía la frase "Esta es casa de Dios y puerta del Cielo". Pues bien, una mañana apareció pintada en la entrada de su escuela: "Esta es casa del diablo y puerta del infierno".

Asimismo, agresiones directas: por ejemplo, piedras arrojadas 43 durante algún acto de graduación o a la salida de clase, ilustraban sobre situaciones de violencia física que provocaban estupor en las afectadas. En ese sentido, las propias circunstancias del director de la Escuela Normal de Paraná, impedido de dar sepultura a su esposa muerta, por razones dogmáticas, habida cuenta de que los cementerios eran patrimonio eclesiástico, suman en un listado menos anecdótico de lo que a primera vista podría suponerse.

Limitarse a nombrar las diversas expresiones de rechazo de que fueron

41 Jennie Howard venida en 1883 , durante la presidencia de Roca, relató sus vivencias en un librito llamado In distant climes and other years (publicado en español bajo el título de En otros años y climas distintos).

42 Elizabeth Peabody, la ya citada hermana de Mary Mann, fue educadora, iniciadora de los primeros Jardines de Infantes en los Estados Unidos; también fue activista de la liberación de los esclavos, feminista y sufragista.

43 Ver en un párrafo anterior, la mención a hechos comparables citados por Frances Wood en Virginia. 
objeto, en los términos de anécdotas y/o prejuicios, ${ }^{44}$ es insuficiente para un análisis de más amplio alcance. Contribuyen a reafirmar, por una parte, que el optimismo de Sarmiento, ya citado, en la práctica, fue sólo eso: optimismo no corroborado por el curso de los acontecimientos. Pero, también, la medida en que se abría una confrontación que, en adelante tendería a profundizarse.

\section{Extranjeras...?: el maestro en el discurso clerical}

Durante el período en cuestión se traba una lucha por la expropiación de resortes de poder por parte del Estado vinculados a la laicización:45 registro de las personas, cementerios, matrimonio, educación, etc.

La presencia de las maestras, una de las cuales sería directora de la Escuela Normal Nacional de Córdoba, que se abría en simultáneo con el debate en el congreso Nacional de la ley 1420, reactivó una resistencia ya planteada en el período previo.

Sin subestimar la validez de posibles objeciones, ya que las maestras hablaban, al principio, un dificultoso español, las agresiones directas que las afectaron, más allá del clima de anarquía general se inscribieron en un conflicto menos trivial de lo que, a primera vista, se aprecia. Es posible sostener que las diversas manifestaciones contra las maestras, así como contra Juana Manso, pueden ser vistas como dimensión de una estrategia más amplia de rechazo por la laicización, que, en la segunda mitad del siglo XIX, era un nudo en el que se entrelazaba la inclusión de la cultura universal y la convivencia de cultos. Asimismo, si bien menos registrado en los relatos, el inicio de la lucha por el derecho de las mujeres a una participación activa, en todos los espacios.

Habrían sido la trayectoria que las precedía, tanto en el campo pedagógico como su formación intelectual, las razones que habían despertado el entusiasta interés de Sarmiento. Y, según surge del análisis, el fundamento de la encendida oposición de la que fueron objeto.

Estas profundas controversias se inscribían en un conflicto más amplio: la negativa del liberalismo a la firma de un Concordato con la Santa Sede que

44 Ver, por ejemplo, el propio relato de Luiggi, que, sin embargo, aporta tanta información.

45 Los 80 es el período de pleno auge de avance del laicismo que tenderá a moderarse en adelante. 
replanteó una confrontación en todos los terrenos. Consecuentemente, la puesta en práctica de mecanismos alternativos de presión sobre el liberalismo, que nunca abandonaron los propósitos iniciales de asegurar el control de la educación y la cultura. En el marco de esta contraofensiva, declaradamente política, ${ }^{46}$ se reactivaba un conflicto, de larga data entre Iglesia y Estado 47 que, en lo referido a educación, se planteaba como una disputa por el modelo escolar, curriculum, versiones de la historia, de los libros de texto, etc,

Algunos elementos permiten caracterizar la estrategia discursiva que enfrentó a los propósitos laicizantes del liberalismo. Uno de los conflictos centrales planteados giró en torno a la religión del maestro, que, en el discurso dogmático, definió un principio de legitimidad, sustentado en una identidad nacional = nación católica, que, consecuentemente, remitía a argumentos basados en el Derecho Canónico. 48

Desplegados en un escenario político, era presentados para el rechazo de la heterodoxia, de la que, en esa constelación discursiva, se hacían pasibles las docentes. Cabe recordar, en esa línea de análisis, que la propia ley 1420 fue denunciada, por su presunta condición de extranjerizante, desde el discurso clerical. De tal modo, la confrontación participaba de diferencias irreconciliables en torno al modelo escolar y el rol del maestro en su preservación.49 Confrontando con la ofensiva por laicizar, en todas sus dimensiones, el ámbito escolar, el maestro debía garantizar que planes y programas, versiones de la

\footnotetext{
46 "No siendo la política otra cosa que el gobierno de las sociedades y l dirección práctica de los asuntos públicos, evidente es que, ante todo, debe ser católica, es decir conforme a las leyes de Dios y a la enseñanza de la Iglesia (...) se ve pues que no es posible ser sinceramente católico sin ser al mismo tiempo clerical, es decir partidaria de las enseñanza del clero o de la Iglesia, en el orden social y público(...)”. El Eco de Córdoba, 9-09-81. El peso relativo de fracciones de matriz clerical hicieron de Córdoba uno de los escenarios centrales de expansión de un conflicto en el se anudaban la lucha por la laicización de la Universidad con el ingreso de docentes procedentes de los EEUU. Convergen, en ese punto, los conflictos vinculados con la incorporación -o su rechazo- de la ciencia y la cultura universal, bajo el supuesto de su incompatibilidad con el Derecho Canónico. Para ampliar el tema ver Silvia Roitenburd (2000).

47 Era el que refería a la firma de un Concordato con la Santa Sede, según el que, el Papado, como centro de poder, tendría derecho a ejercer el control sobre aspectos que se señalaban como de su incumbencia en detrimento de los poderes del Estado. "Los puntos en controversia (entre la Iglesia y el Estado) (el matrimonio, la educación que son disciplinados por el derecho canónico, vale decir, se aplica en el ámbito estatal un derecho que le es extraño. Por eso los católicos, en base a un derecho que le es extraño al Estado, pueden hasta anular el matrimonio, a diferencia de los no católicos, cuando el ser o no ser católico debería ser irrelevante a los efectos civiles(...)" Ver Antonio Gramsci (1971).

48 Remito a Silvia Roitenburd (2000).

49 Ver Debate Legislativo Ley 1420, Prólogo Gregorio Weinberg.
} 
historia y de civismo, se mantuvieran en los límites de una identidad dogmática. De tal modo, mucho más que una cuestión religiosa, la religión del maestro se convertía en una de las claves fundamentales de garantía de una sociedad para el control.

En esta articulada contraofensiva se inscribió, en primer lugar, la Pastoral del Vicario Clara, máxima autoridad eclesiástica, en abril de 1884, en Córdoba, en el marco del debate de la ley 1420 , de enseñanza laica.50 Su expreso objetivo: impedir la apertura de la Escuela Normal Nacional de Córdoba.51. Uno de los blancos fundamentales de la Pastoral, fueron las maestras norteamericanas por su condición de extranjeras $=$ protestantes .

A ningún padre católico es lícito enviar sus hijas a semejante escuela (...) con maestras protestantes. $5^{2}$

La Pastoral contra el laicismo y, muy específicamente, contra la presencia de maestras protestantes para las Escuelas Normales, planteó un conflicto de orden político-educativo, presentado por el discurso clerical como la religión del maestro que, en adelante, se profundizará en la Argentina. Frente al tono electrizante de dicho documento eclesiástico, Frances Amstrong, directora designada de la Escuela, solicitó una entrevista ante el Vicario, manifestando la irrevocable voluntad -de las docentes, por cierto- de respetar la libertad de cultos. La señorita Amstrong no parecía preparada para la situación de extrema tensión en la que se vio envuelta por una razón que, a su juicio, no se vinculaba con los objetivos de orden pedagógico que las habían movilizado. Su visita al Vicario Clara, tuvo el fin de plantearle su disposición a que en la Escuela Normal se respetaran todos los cultos.53 A ese fin, en la audiencia que el Vicario le concedió, a la que acudió acompañada de la esposa del Gobernador Gavier, se comprometió, incluso, a aceptar el dictado de clases de religión católica, para quienes lo solicitaran. Pero no era ese el espíritu de la Pastoral.

Como es sabido, las controversias con el Gobierno Nacional, empeñando

\footnotetext{
50 Ver el intenso debate entre clericales y liberales en el Congreso Nacional.

51 Unos años más tarde, Alejandro Carbó.

52 Un segundo punto de la Pastoral conminaba a la Universidad a impedir la defensa de la tesis de Ramón J. Cárcano "Los hijos adulterinos, incestuosos y sacrílegos, por anticatólica y, en tercer lugar, condenaba como impíos tres periódicos: El Interior, (dirigido por Cárcano) La Carcajada y El Sol de Córdoba. La Pastoral se reproduce en Cayetano Bruno (1981: 98) .

53 Los testimonios indican que, aún en esas circunstancias, las maestras norteamericanas, de religión protestante, daban muestra de valores comunes, incluso, cuando entraban a rezar en el templo católico, a falta de uno de su propia confesión religiosa.
} 
en sostener un plan de estudios enteramente laico, se manifestaron en la indignación de los funcionarios del mismo ante la posición de autoridad del Obispo en un asunto público,54 incluso sus controversias con la actitud sumisa de Frances, en alguna medida, atrapada en una lucha política que, probablemente, no terminaba de comprender.

Se podrían desplegar algunas conclusiones provisorias: docente para quien la cuestión religiosa no representaba un conflicto, es probable que no terminara de comprender los motivos del tono de confrontación de la Pastoral, la postura intransigente del eclesiástico ni las agresiones de las que eran objeto en forma frecuente.

Es importante dejar registro de otros aspectos de esta contraofensiva manifiesta ante el interés despertado por el modelo de los EEUU, visible tanto en Juana Manso como en Sarmiento, y la consecuente contratación de maestras de ese origen, que remiten a propuestas provenientes de una matriz discursiva excluyente.

Las argumentaciones, en el campo del derecho, referidas a principios de legitimidad dogmática, fundamentaron sucesivos proyectos de ley, tanto en la Legislatura Provincial como en el Congreso Nacional. Consecuentes con dicho criterio de legitimidad, se planteó la contratación de los Hermanos de las Escuelas Cristianas, procedentes de Francia,55 mediante la asignación de fondos públicos para la educación nacional. Proyectos de ley presentados en forma reiterada, según tenemos registro, desde la década de los 70 y reactivados en 1880 ante el Congreso Nacional, hasta 1884, en simultáneo con el debate de la ley 1420.

Es interesante dar cuenta de la contra-ofensiva, en este aspecto, porque se despliega a partir de una construcción discursiva que define lo extranjero en sus propios términos así como lo nacional, en equivalencia con una versión

\footnotetext{
54 Respecto al mismo, remito a Silvia Roitenburd (2000).

55 Hermanos de las Escuelas Cristianas (FSC), Fratum Scholarum Christianorum, más conocidos en algunos sitios como Hermanos de La Salle, es una congregación de maestros laicos fundada por San Juan Bautista de La Salle. No forman una orden religiosa tradicional y se encuentran dentro de la Iglesia Católica en el espacio de la comunidades de vida consagrada. Este instituto fue aprobado por la Santa Sede como una congregación religiosa el 26 de enero de 1725 por el papa Benedicto XIII. Llevan una vida al modo de las congregaciones; sin embargo, los hermanos lasallistas están facultados para ser ministros de la comunión y es común que en sus colegios se celebren misas en determinadas épocas y ocasiones especiales, donde colaboran con el sacerdote en el momento de la comunión.
} 
dogmática de la religión católica. ${ }^{6}$

Tales docentes-miembros de una congregación, eran portadores de un sistema de valores y jerarquías instauradas por una autoridad eclesiástica a quien debían obediencia, compatibles con un modelo educativo tradicional: criterios de rígidas jerarquías, castigos físicos, diferenciación según procedencia social, etc.

Por otra parte, el idioma de estos maestros -el francés- remite a la muy razonable objeción que se formulara ante las maestras cuya lengua materna era, por cierto, el inglés.

Quienes objetaron con más énfasis la condición de extranjeras de las maestras y los presuntos riesgos consecuentes para la defensa de nuestra identidad, no se hicieron cargo de la contradicción de una identidad nacional, difundida a partir de quienes provenían de una tradición y cultura autoritaria que se procuraba superar. Aplicaron, en este caso, un argumento en el que su procedencia quedaba subordinada al elemento que el discurso concebía como rasgo nodal de nuestra identidad nacional: la religión católica. ${ }^{57}$

Cuestión que se inscribía en un más amplio debate en torno a la cultura universal y a los límites al ingreso de los nuevos aportes de la ciencia y la experimentación, que habían llevado a Sarmiento, al mismo tiempo, a la apertura del Observatorio y de la Academia de Ciencias. ${ }^{8}$ Quedan planteados interrogantes sobre las maestras, que convergen en este punto: Amadeo Jacques -científico y filósofo francés exiliado luego de la Revolución de 1848-, contratado en 1862 por el entonces Presidente Bartolomé Mitre para las transformaciones en la Universidad, y Benjamin Gould, director del

56 En cuanto a las consecuencias, en un largo plazo de este discurso, remito a Silvia Roitenburd (2000).

57 El mismo que aplicó, entre otros, el propio ex ministro de Sarmiento, Nicolás Avellaneda llamaba a la ley 1420 extranjerizante.

${ }^{8}$ Durante su misión diplomática -como embajador en 1864- Sarmiento visitó también al astrónomo Benajmín Gould, a quien contrataría en 1870 para el Observatorio de Córdoba, Por su parte, Mary Mann le había sugerido a Sarmiento nombrar al Rev. William Henry Channing (1810-1884) -sobrino de William Ellery Channing- como presidente de la Universidad de Buenos Aires. Esto permite abrir algunos interrogantes poco explorados en los que se visualiza un proyecto que apunta a la formación de docentes para el nivel primario y Jardin de Infantes. Poco conocida también ha sido la compleja postura sostenida en relación a la Universidad: en el preciso espacio en el que Mitre libraba una ofensiva para la transformación de la primera Universidad del Río de la Plata -la de Córdoba-, Sarmiento, reacio a esta estrategia, funda instituciones cuyo carácter de introducción de la investigación y la ciencia modernas indican que el conflicto no le era nada ajeno. 
Observatorio creado por Sarmiento, en 1870, eran extranjeros, es decir, nacidos en otro país. Pero, en un análisis de su aporte a la ciencia nacional, entonces en germen, ¿cuál sería la pertinencia de declararlos enemigos de nuestra nación, lo mismo que a las maestras?

Retomemos una de las líneas sobre las que se desliza el análisis: ni las agresiones, de las que fuera objeto Juana Manso, tanto las que la definieron como extranjerizante como las que ironizaron sobre sus transgresiones, cuanto las, en apariencia, grotescas alusiones a su vida privada como las que asombraran ingratamente a las maestras norteamericanas, deben ser vistas en una perspectiva capaz de dar cuenta de su inserción en una estrategia políticocultural más amplia. A tal fin, reconstruir el escenario, en particular el que desembocó en la conflictiva de los años 80 del siglo XIX y del período previo, permite advertir que se trató de una estrategia de oposición al liberalismo, entonces en su momento más decidido de avance del laicismo, que, a la vez que difundía posiciones doctrinarias a favor de valores de control social, los defendía en los espacios públicos y legislativos.

Las diversas perspectivas permiten reconstruir, en parte, el escenario en el que debía desenvolverse la nueva práctica pedagógica. Habían vivido, como maestras, la experiencia, en la escuela y en el aula, con alumnos que requerían particular atención y aceptaban desafíos de ese tipo. No esperaban una confrontación semejante, que las convertía en el centro de una lucha entre autodesignados "católicos" y liberales.59

Que ellas tuvieran una cuota de ingenuidad y/o falta de una clara información acerca del espacio en el que debían ejercer su tarea pedagógica concuerda con la sorpresa ante el hecho de que las condiciones del mismo, no sólo por la inseguridad manifiesta por la guerra civil, los ataques de los indios, alojamiento precario, salubridad e higiene, eran bastante distintas a las que estaban acostumbradas. No menos impacto habría producido el rechazo provocado por el conflicto en torno a la religión de las maestras.

Ahora bien: si volvemos sobre el punto antes mencionado y nuevamente lo inscribimos en la estrategia discursiva clerical, queda integrada la postura, coherente con el modelo de país que se postulaba. La condición de extranjero,

59 En otros trabajos, he caracterizado el clima de confrontación creado en el período del debate de la ley 1420 en el Congreso Nacional 
más allá de la supuesta paradoja, no se vincula, necesariamente, con el lugar de nacimiento, ni con el idioma, sino con el rasgo que es presentado como nodal en la definición de la identidad nacional. De tal modo, las maestras quedaron incluidas en el campo enemigo = extranjeras, no sólo o no tanto por su condición de norteamericanas, sino de heterodoxas. Esto, en consideración vinculada a su formación pedagógica y trayectoria en el campo, y a su compromiso con valores que las ligaban a otros espacios y grupos sociales.

En esta línea de investigación, las dificultades a veces extremas, dejan de ser meras anécdotas para revelar la infinita gama de conflictos que debían afrontar las valientes. ${ }^{60}$ Agrego una reflexión: llamarlas valientes y/o mujeres fuertes, como son evocadas por algunos escritos, es una manera de recuperarlas del olvido. Sin embargo, siguen en una especie de vitrina como curiosidad, algo excepcional, que se menciona por esa circunstancia. Quedan fuera de un análisis más complejo que permite vislumbrar tempranas luchas por la participación entendida como acción.

\section{Reflexiones finales}

Sarmiento, entre Juana Manso y las maestras norteamericanas, alude a lo que se presenta como evidencia compartida: fue el impulsor de la instrucción primaria en la Argentina. Las reflexiones que se esbozan, sin embargo, no proponen reafirmar el lugar que ya ocupa en el bronce de la historia oficial. Apuntan, más bien, a dar cuenta de una trayectoria compleja, que recorrió, en muchos tramos, junto a figuras que fueron opacadas por los relatos hegemónicos. Cuestionado a partir del significado de la civilización, en su discurso, parece haber encontrado, a través de su diálogo con una mujer nacida en este territorio, así como con otra/s, extranjeras, sus vetas más abiertas a la cultura universal y a los conflictos de un sistema que mostraba sus fisuras.

Es posible sostener que la educación como aspecto nodal de integración a la cultura de la mujer y su rol en la sociedad, su derecho a la participación en campos vedados, la coeducación, etc. se desplegaron en el escenario en el que se definía la llamada Organización Nacional. Su inscripción en la trama del

6o Buena parte de la información biográfica sobre las maestras norteamericanas se encuentra en Alice Houston Luigi (1959). 
proceso, que culminó con el dictado de la ley 1420, parece imprescindible.

Veladas por las versiones oficiales de la historia -o bien recuperadas casi como curiosidad-, quedaron las mujeres que, sin renunciar a su condición de madres y a sus expectativas de matrimonio, se atrevieron a participar de asuntos de hombres: estudiar y trabajar. También, a demandar participación política, entendida no sólo como el derecho al sufragio -aunque todas fueron sufragistas - sino a la creación artística, literaria, a la investigación científica, etc. y, en fin, a atravesar el océano hacia un destino incierto.

Juana Manso pensó en problemas comparables a los que ocupaban a otros letrados de su época. Pedagoga, escritora, traductora, etc., publicó obras didácticas, dramas y poesías; dictó conferencias, redactó artículos periodísticos y promovió la apertura de bibliotecas y entidades con fines culturales. Expuso en su obra la articulación de demandas vinculadas con el rol de la mujer, con el derecho al acceso a la cultura por parte de los desfavorecidos -incluyendo a la infancia-, a la vez que por una participación incluyente, rasgo no siempre presente en otras figuras de su generación. La información sobre su obra es escasa y disgregada. Más allá, incluso, de la valorización decidida que recibiera por parte de algunos de sus contemporáneos que sí pasaron a la historia, como es el caso del propio Sarmiento, José Mármol y otros.

Este recorrido a través del que se recuperan las voces sofocadas de quienes no tenían espacio propio en el escenario político, permite reconstruir una imagen más compleja que la de una lineal formación del sistema educativo en una nación incipiente. Y, sobre todo, muestra las vetas borroneadas de la propia trayectoria de una figura controvertida. Es posible sostener que Sarmiento era, sobre todo, un político con un proyecto educativo estrechamente funcional al mismo. Su enfática convicción en cuanto al rol de la instrucción masiva así como una práctica decidida en esa dirección, lo ubicaron en el panteón de los héroes de la Argentina como padre del aula. No hubo espacio para ninguna madre del aula, aún en el caso que tal rótulo tuviera sentido.

Las maestras quedaron grabadas en la memoria de algunas escuelas normales, habría que ver en cada caso, abriendo una tradición que no trascendió más allá del ámbito escolar. Esto permite formular algunos interrogantes en cuanto a las razones por las que fueron combatidas y como contracara, las que mantuvieron su memoria en tantas instituciones de ese tipo 
en diversos rincones del país como Mary Graham que estuvo en San Juan y en La Plata(:), y cuya Escuela Normal lleva su nombre.

Esbocé unas breves líneas de un problema más amplio sobre la capacidad hegemónica de una versión de la identidad basada en el rechazo a la diversidad y en la reafirmación del rol de la educación como medio de control.

En términos de problematización, es posible desplegar algunos interrogantes: ¿qué mandatos transgredieron, o más bien, desde que discurso fue posible presentarlas como heterodoxas? Entonces: ¿desde dónde, es decir desde que lugar del espectro ideológico, desde qué trama discursiva, se planteó la confrontación de la que fueron objeto?

No es sólo que hace más de cien años Juana Manso o las docentes fueron acusadas de extranjerizantes y/o extranjeras, en su significado más peyorativo, sino de transgredir valores instaurados $\mathrm{y}$, presuntamente, inamovibles, abriendo una lucha por la imposición de valores autoritarios en el sistema educativo y en toda la sociedad. En esa dirección, reactivar la memoria sobre las huellas de quienes abrieron las escuelas normales permite avanzar en el análisis de una oposición que objetaba, mucho menos que su extranjeridad, los valores universales que pretendían transmitir a través de la escuela.

\section{Bibliografía}

ARENDT, Hannah. Sobre la Revolución. Madrid: Alianza editorial, 2006.

BRUNO, Cayetano. Historia de la Iglesia en la Argentina. Buenos Aires: Don Bosco, 1981.

CARLI, Sandra. Modernidad, diversidad cultural y democracia en la historia educativa entrerriana. IN: PUIGGRÓS, Adriana (dir). La educación en las Provincias y Territorios Nacionales. Buenos Aires: Galerna, 1993.

Debate Legislativo Ley 1420. Prólogo Gregorio Weinberg.

GRAMSCI, Antonio. La política y el estado moderno. Barcelona: Península, 1971.

HALPERIN DONGHI, Túlio. Historia de la Universidad de Buenos Aires. Buenos Aires: EUDEBA, 1962.

. Una Nación para el Desierto Argentino. Buenos Aires: CEAL, 1982.

LUIGGI, Alice Houston, Sesenta y Cinco Valientes. Sarmiento y las Maestras Norteamericanas. Buenos Aires: Biblioteca Lincoln, 1959.

ROITENBURD, Silvia. Educación en los dogmas para un proyecto global restrictivo, Nacionalismo Católico, Córdoba (1862-1943). Córdoba: Ferreyra Editor, 2000. 
Silvia N. Roitenburd

Sarmiento: entre Juana Manso y las maestras de los EEUU. Recuperando mensajes olvidados

SALVADORES, Antonino. La instrucción primaria desde 1810 hasta la sanción de la Ley 1420. Buenos Aires: Consejo Nacional de Educación, 1941.

SARMIENTO, Domingo F. Memoria sobre Educación Común, 1856.

TABORDA, Saúl. Investigaciones Pedagógicas. 4 tomos. Córdoba: Ateneo Filosófico de Córdoba, 1951.

Colaboração recebida em 07/05/2009 e aprovada em 24/05/2009. 